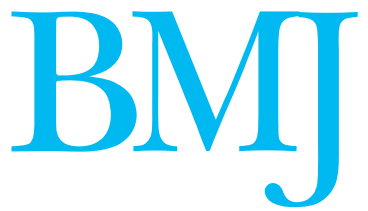

\title{
Treatment of irritable bowel syndrome
}

\author{
Strategies involve single receptor blockade and non-pharmacological interventions
}

I rritable bowel syndrome is characterised by diverse symptoms including abdominal pain, altered bowel function (increased bowel frequency, constipation), bloating, abdominal distension, the sensation of incomplete evacuation, and the increased passage of mucus. ${ }^{\mathrm{w} 1}$ No unifying hypothesis explains all these symptoms, and no single agent will alleviate all components of the symptom complex. The currently favoured model to explain the symptoms includes central and end organ components. These may be combined into an integrated hypothesis that incorporates psychological factors (stress, distress, affective disorder) and dysfunction of the gut (disorders of motility, visceral hypersensitivity). ${ }^{1}$ Current standard drug treatment generally entails a symptom directed approach with drugs aimed at pain, constipation, and diarrhoea. ${ }^{2}$ Development of new drugs has focused mainly on agents that modify the effects of 5-hydroxytryptamine (5-HT) in the gut. Alternatives to this single receptor approach exist, although not all patients respond to educational and psychological interventions, and treatment with drugs will remain an option for nonresponders.

As a mediator of the motor and secretory responses to the ingestion of food, 5-HT has an important physiological role. Growing evidence shows that some aspects of the pathophysiology of irritable bowel syndrome may affect the 5-HT axis. ${ }^{\text {w2 }}$ Specific 5- $\mathrm{HT}_{3}$ and $5-\mathrm{HT}_{4}$ receptors have been identified as therapeutic targets.

Alosetron and cilansetron, which are $5-\mathrm{HT}_{3}$ receptor antagonists, were devised to reduce pain and retard transit and therefore be beneficial in irritable bowel syndrome that manifests predominantly as diarrhoea. Randomised controlled trials indicate that both have some efficacy in patients with diarrhoea predominant irritable bowel syndrome, although alosetron is effective only in women. ${ }^{3}$ Although alosetron was licensed in the United States in 2000, it was subsequently withdrawn because many patients developed ischaemic colitis and severe constipation. ${ }^{\text {w3 }}$ Many of these patients required admission to hospital, and three of them died. Ischaemic colitis has also been reported with cilansetron and seems likely to be a class specific adverse effect. Recent evidence shows that ischaemic colitis may be increased in patients with irritable bowel syndrome, ${ }^{4}$ and that this may be influencing the effect of alosetron adversely. The Food and Drug Administration, however, has challenged this
The second problem relates to whether the statistically significant therapeutic gain of about $12 \%$ over placebo translates into a clinically important benefit for patients with irritable bowel syndrome. A group of experts has advised that a $10-15 \%$ therapeutic gain would be appropriate for a new drug for irritable bowel syndrome, although this statement seems to lack evidence $^{6}$

Tegaserod, a 5- $\mathrm{HT}_{4}$ receptor partial agonist and a prokinetic in the gut, is effective in women with constipation predominant irritable bowel syndrome. The therapeutic gain over placebo varied substantially in different trials at 5-20\%, again raising the question whether this is a clinically important effect and whether a similar therapeutic gain might be obtained with a simple laxative or soluble fibre. A Cochrane review confirms the drug's efficacy in improving the overall symptoms in irritable bowel syndrome, with a number needed to treat between 14 and 20, but finds no effect on individual symptoms of pain and discomfort. $^{7}$ Tegaserod is now available in the United States and some other countries for the treatment of constipation predominant irritable bowel syndrome in women. It is still under evaluation by the European Agency for Evaluation of Medicinal Products. Tegaserod has also been linked to ischaemic colitis, ${ }^{8}$ but this assertion has been rebutted on the basis that this merely represents the incidence in the general population. ${ }^{9}$

The science linking 5-HT and irritable bowel syndrome is appealing, and some progress has been made in translating this knowledge into new treatments, however, we still have no pharmacological intervention that will resolve all aspects of the symptom complex of irritable bowel syndrome in men and women. An agent directed at a single gut receptor is unlikely to cure irritable bowel syndrome.

What other options might be worth exploring? The importance of psychosocial factors in the development of irritable bowel syndrome has been recognised for decades. Psychological interventions (psychotherapy, short and long term hypnotherapy, cognitive behaviour therapy) and antidepressants (low and conventional doses) are effective. Cognitive behaviour therapy has an impressive therapeutic gain of 33\% over control. ${ }^{10}$ Multidisciplinary education and comprehen- 
sive self management programmes in women have also been shown to work. ${ }^{11} 12$

Thompson, however, said recently that most patients with irritable bowel syndrome require no drug treatment. ${ }^{\mathrm{w} 4}$ For most patients, irritable bowel syndrome is an intrusive and sometimes debilitating condition, but it is never fatal in itself. Therefore, we must be certain that any new treatment is truly effective and has a clinically significant benefit over placebo, and must do no harm.

Michael J G Farthing professor of medicine

St George's Hospital Medical School, London SW17 0RE (m.farthing@sghms.ac.uk)

Competing interests: MF has acted as an adviser to Novartis Pharmaceuticals, GlaxoSmithKline, Pfizer, and Solvay Pharmaceuticals with respect to the development and evaluation of new drugs for the treatment of irritable bowel syndrome.

1 Mayer EA, Collins SM. Evolving pathophysiologic models of functiona gastrointestinal disorders. Gastroenterology 2002;122:2032-48.
2 Farthing MJG. Treatment options in irritable bowel syndrome. Best Pract Res Clin Gastroenterol 2004;18:773-86.

3 Camilleri M, Chey WY, Mayer EA, Northcutt AR, Heath A, Dukes GE, et al. A randomized controlled clinical trial of the serotonin type 3 receptor antagonist alosetron in women with diarrhoea-predominant irritable bowel syndrome. Arch Intern Med 2001;161:1733-40.

4 Higgins PDR, Davis KJ, Laine L. Systematic review: the epidemiology of ischaemic colitis. Aliment Pharmacol Ther 2004;19:729-38.

5 Brinker A, Avigan M. Epidemiology of ischaemic colitis. Aliment Pharmacol Ther 2004;20:697-9.

6 Corazziari E, Bytzer P, Delvaux M, Holtmann G, Malagelada JR, Morris J, et al. Clinical trial guidelines for pharmacological treatment of irritable bowel syndrome. Aliment Pharmacol Ther 2003;18:569-80.

7 Evans BW, Clark WK, Moore DJ, Whorwell PJ. Tegaserod for the treatment of irritable bowel syndrome. Cochrane Database Syst Rev treatment of initable 2004;(1):CD003960.

8 Brinker AD, Mackey AC, Prizont R. Tegaserod and ischemic colitis. N Engl J Med 2004;351:1361-2.

9 Joelsson BE, Shetzline MA, Cunningham S. Tegaserod and ischemic colitis. N Engl J Med 2004;351:1363.

10 Saito YA, Prather CM, Van Dyke CT, Fett S, Zinsmeister AR, Locke GR. Effects of multidisciplinary education on outcomes in patients with irritable bowel syndrome. Clin Gastroenterol Hep 2004;2:576-84

11 Heitkemper MM, Jarrett ME, Levy RL, Cain KC, Burr RL, Feld A, et al. Self-management for women with irritable bowel syndrome. Clin GastroSelf-management for wom
enterol Hep 2004;2:585-96.

12 Drossman DA, Toner BB, Whitehead WE, Diamant NE, Dalton CB, Duncan S, et al. Cognitive-behavioral therapy versus education and desimipramine versus placebo for moderate to severe functional bowel disorders. Gastroenterology 2004;125:249-53.

\title{
Primary care for children in the 21 st century
}

\author{
General practitioners must adapt to the changed spectrum of illnesses
}

$\mathrm{T}$ The British model of general practice is rightly admired. ${ }^{12}$ Explicit responsibility for a defined population facilitates a public health dimension to health care. The training emphasises teamwork, consultation skills, management of undifferentiated symptoms, and the integration of psychosocial and biological aspects of health and illness in the context of the family and community. These skills are crucial for working with children and young people and the recently published national service framework for children has a whole section on primary care. ${ }^{3}$ w1 Therefore, to question the future of children's health care in general practice may seem perverse, but there are several causes for concern.

Although serious acute childhood illness has become less common, both professionals and parents worry about overlooking potentially life threatening conditions. When a child is ill outside surgery hours, parents accept that they are unlikely to see their usual doctor and the new contract permits general practitioners to opt out of 24 hour responsibilities. ${ }^{\text {w2 }}$ w3 Out of hours services, such as NHS Direct, often direct parents to a primary care assessment facility or a hospital emergency department. Even if primary care organisations can sustain 24 hour cover, more parents may well decide to bypass primary care and seek emergency care in hospitals, accelerating the move towards centralised emergency services and more short stay admissions. ${ }^{\mathrm{w} 4 \mathrm{w} 5}$

Rare complex paediatric conditions need specialised management, but chronic neurological, psychosocial, and mental health problems (in particular conduct and behavioural disorders) make up a large part of modern paediatrics, ${ }^{4}$ yet their care remains fragmented and the resources allocated inadequate. ${ }^{5}$
General practitioners have yet to take on a major role in managing chronic disorders, many of which persist into adult life, ${ }^{6}$ although children's trusts could in the future facilitate cooperation between health services and the education and social services provided by local government.

The 1990 contract encouraged general practitioners to provide child health surveillance programmes. They are well placed to understand how individual social circumstances might influence each child's health and development. ${ }^{\mathrm{w} 6}$ The growing evidence for child health screening and promotion in preschool facilities and schools underlies government support for a child health promotion programme. ${ }^{3 \text { w7 } \mathrm{w} 8}$

Although some doctors enjoy preventive care and caring for well children, many believe that this is best delivered by other professional staff such as health visitors. The latter, however, work increasingly on a geographical basis separate from general practices. Physical examination, once the preserve of doctors, can be undertaken by appropriately trained nurses and midwives, at least where the newborn is concerned and non-medical staff are increasingly functioning as independent practitioners. ${ }^{\text {w9 }}$ Health promotion for teenagers is also problematic; they often prefer clinics near their school or college for sensitive issues like sexual health because of concerns about the privacy and confidentiality offered by their local general practice, despite many practices having sought to reassure young people by establishing special teenage clinics. ${ }^{7}$

In other European Union countries and the United States, ${ }^{89}$ office based paediatricians provide most care,

Extra references w1-w12 are on bmj.com 